Uluslararası Sosyal Bilgilerde Yeni Yaklaşımlar Dergisi,2020, 4(1), 79-93

International Journal of New Approaches in Social Studies, 2020, 4(1), 79-93

\title{
Hayat Bilgisi Dersinde Okul Dışı Öğrenme Ortamlarının Kullanımına Yönelik Sınıf Öğretmenlerinin Görüşleri
}

\author{
Aytekin KARBEYAZ ${ }^{1 *} \&$ Murat KURT ${ }^{2}$
}

Gönderilme Tarihi:6 Nisan 2020

Kabul Tarihi: 15 Haziran 2020

DOI: $10.38015 /$ sbyy. 715208

\begin{abstract}
$\ddot{\text { Öz: }}$
Sürekli değişimin yaşandiğı 21. yüzyılda ĕ̌itim öğretimin de bu değişimden etkilenmesi kaçınılmazdır. Eğitimciler sınıfta gerçekleştirilen ĕgitim faaliyetlerinin tamamlayıcısı olan başka arayışlara gitmişler ve bunlardan biri de okul dışı ögrenme ortamlarıdır. Bu çalışmada amaç; ilkokul 3.sınıf Hayat Bilgisi dersi "Doğada Hayat” "̈nitesinde okul dışı ögrenme ortamlarının kullanımına yönelik sınıf ögretmenlerinin görüşlerini belirlemektir. Çalışmada betimsel tarama metodu kullanılmıştır. Katılımcılar amaçlı örneklem seçme yöntemi içerisinde bulunan ölçüt örneklem yöntemi ile 2019-2020 öğretim dönemi Sivas'ın Yıldızeli ilçesinde devlet okulunda görevli, sinıfinı genel meslek yaşantısı içerisinde son beş yılda en az bir kez okul dışı öğrenme ortamlarına götürmüş sınıf ögretmenleri ölçüt olarak belirlenerek aralarından 10 kişi seçilmiştir. Veriler araştırmacılar tarafindan oluşturulan yart yapılandırılmış görüşme formu aracılığıyla elde edilmiştir. Nitel verilerin analizinde kullanılan betimsel analiz yönteminden yararlanilarak önceden belirlenen temalar çerçevesinde yorumlanmıştır.

Yapılan araştırma ile sınıf öğretmenlerinin elde edilen görüşlere göre ile; öğrencilerin okul dışı ögrenme ortamlarında gerçekleştirilen etkinlikler sayesinde yaparak yaşayarak öğrenmeyi sağladığı, öğrenilen bilgilerin daha kalıcı olduğu ve okul dışı ögrenme ortamlarında gerçekleştirilen etkinliklerin sınıfta yapılan ögretimin tamamlayıcısı olduğu, Hayat Bilgisi dersi "Doğada Hayat” ünitesi kazanımlarının okul dışı ortamlarda işlenmesinin en fazla Fen Bilgisi dersine katkı sağladı̆̆ düşündükleri sonucuna varlmıştır.Öğretmenlerin görüşlerine göre dayalı olarak okul dışı ortamlarında görevli rehber personele pedagojik eğitimlerin verilebileceği gibi önerilerde bulunulmuştur.
\end{abstract}

Anahtar Kelimeler: Okul dışı öğrenme, hayat bilgisi, kalıcılık.

\begin{abstract}
:
In the 21st century, where continuous change is experienced, it is inevitable that education and training will be affected by this change. The educators have gone to other searches that are complementary to the educational activities carried out in the classroom, and one of them is out-of-school learning environments.

In this study, the opinions of the classroom teachers about the use of out-of-school learning environments in 'the life in nature unit' of primary school 3rd grade life studies course were investigated. Descriptive scanning method was used in the study. With the criterion sampling method in the sample selection method for the participants 2019. 2020 academic year, working in public school in Ylldizeli district of Sivas, 10 teachers were selected from among the class teachers who took their class to out-of-school learning environments at least once in the last five years within their general
\end{abstract}

\footnotetext{
${ }^{1}$ Milli Eğitim Bakanlığı, Türkiye. Orcid ID: 0000-0002-1483-5581

${ }^{2}$ Amasya Üniversitesi, Türkiye. Orcid ID: 0000-0003-1155-9339

*Sorumlu Yazar (Corresponding Author): aytekinkarbeyaz@ hotmail.com
} 
general professional life. The data were obtained through a semi-structured interview form created by the researchers. Descriptive analysis was used in the study.

According to the opinions of classroom teachers; ; provides students to learn by living through activities carried out in out-of-school learning environments, that the information learned is more permanent and the activities carried out in out-of-school learning environments are complementary to the teaching in the classroom, It was concluded that the process of Life Studies "Life in Nature" unit contributes to the Science lesson at most, Based on the results of the study, suggestions such as pedagogical training can be given to the guiding staff in out-ofschool settings.

Keywords: Out-of-school learning, life studies course, permanence.

\section{GíRiş}

İçinde bulunduğumuz 21. yüzyılda sürekli bir gelişim ve değişim yaşanmaktadır. Bu değişimde okulların önemli bir etkisi olmakla birlikte ilkokullarda okutulan Hayat Bilgisi dersinin rolü de yadsınamaz. Hayat bilgisi dersi kişinin toplum hayatına adapte olmasını sağlayan bilgi, beceri ve değerleri kazandırmayı amaçlayan bir derstir (Gündoğan ve Gültekin, 2018). İlkokulda verilen Hayat Bilgisi dersi ile öğrenci kendisini gerçek yaşama hazırlamakta, hayatını programlayabilmekte ve karşılaştıkları problemlere çözüm getirebilmektedir (Gündoğan ve Gültekin, 2018). Ek olarak Hayat Bilgisi, Sosyal Bilimler ile Fen Bilimleri dersine temel teşkil etmesi açısından da önemli görülebilmektedir. Hayat Bilgisi dersi Fen ve Sosyal bilimler dersine temel oluşturmaktadır (Baysal, Tezcan ve Araç, 2018). Böyle olunca önceki sinıflarda oluşabilecek bir öğrenme eksikliği nedeniyle öğrenci ileriki sınıflarda hazırbulunuşluk açısından yetersiz kalabilmektedir. Özellikle de yapılandırmacı anlayışın hâkim olduğu okullarda yapılan eğitim ilk elden gerçekleştirilmektedir. Bu yönden incelendiğinde öğrencilere yaşam becerilerini, bilime dönük ilgi, tutum gibi birden çok farklı yönlerin sadece kitap ve öğretim programları aracılığı ile kazandırılması yeterli olmamaktadır (Şen, 2019). Eğitimciler bu nedenle karmaşık bir yapıya sahip olan öğrencilere bir dersin kazanımlarını öğretmek için farklı arayışlara gitmiştir. Bu duruma okul dışı öğrenme ortamlarında yapılan etkinlikler örnek olarak gösterilebilir. Bilhassa Hayat Bilgisi ders programının bazı kazanımları, sınıf içerisinde etkili bir şekilde öğrenilmesini zorlaştıran yapısından dolayı eğitimcileri okul dışı ortamlara yöneltmektedir.

Bireylere özellikle de içinde bulundukları 21. yüzyılda değişen koşullara ayak uydurmaları için bazı temel becerilerin kazandırılması istenmektedir (Çepni ve Ormanc1, 2018). Öğrencilere bireysel farklılıkları, deneyimleri, yaşam becerileri, plan yapma, karar verme gibi üst düzey becerilerin kazandırılması amaçlanmaktadır (Çepni ve Ormancı, 2018). Problem çözme, iletişim teknolojilerini kullanma, sağlıklı iletişim kurma, yaratıcı olma gibi becerilerin geleneksel yaklaşımın hâkim olduğu okullarımızda kazandırılması güç olmaktadır. Bu durum eğitimcileri eğitim anlamında farklı arayışlara götürmüştür. Çocuklar açısından düşünüldüğünde okul dışı öğrenme ortamlarında yapılan eğitimin daha eğlenceli ve daha kalıcı olması yüksek olasılıktadır. Bu nedenle yapılan bu çalışma ile Milli Eğitim Bakanlığının 2023 Vizyonunda okul dışı öğrenme ortamları (ODÖO) ile ilgili vurgu yapıldığı göz önüne alınarak bu çalışmanın literatüre katkı sağlayacağı düşünülmektedir.

İnsanoğlu değişen dünya koşullarına sürekli kendisini yenileme ve geliştirme mecburiyetindedir. Okul öncesinden üniversiteye kadar öğrencilerin sayısal-sözel yeterliliklerinin yanında eleştirel düşünme, yaratıcılık, problem çözme gibi becerilere de sahip olması istenmektedir (Çepni ve Ormanc1, 2018). Bu da her yaştan bireyin özellikle de geleceğimiz olan öğrencilerin iyi bir eğitim almasını zorunlu kılmaktadır. Bir milletin 
geleceğinden emin olması o milleti oluşturan ulusa bağlıdır (Yağc1, 1998). Böyle olunca bu gelişimin tesadüflere bırakılması düşünülemez. Bu da eğitim sayesinde ve okullar aracılığıyla gerçekleştirilmesi olması gereken bir durumdur. Okullarda verilen eğitim dört duvar içerisinde belli bir program ve mekânda gerçekleştirilmektedir (Şen, 2019). Eğitim; kişinin davranışında kişinin yaşantıları neticesinde kasıtlı olarak ve istendik yönde meydana gelen değişimdir (Ertürk, 1988). Şuan ki anlayış gereği öğretim faaliyetleri öğrenci merkezli olması gerekmektedir. Öğretme ve öğrenme kendiliğinden, doğal olarak gerçekleşen öğrenci merkezli bir faaliyettir (Claiborne, Morrel, Bandy ve Bruff, 2019). Okullarda verilen eğitim öğretim çeşitli dersler aracılığıyla gerçekleştirilmektedir. Bu dersler içerisinde Hayat Bilgisi önemli bir yere sahiptir. Hayat bilgisi dersi; kazanımsal yapısından dolayı yaparak-yaşayarak öğrenmeyi sağlayan etkinlikler aracılığıyla verilebilir. Bu etkinliklere okul dışı öğrenme ortamlarında gerçekleştirilen faaliyetler örnek olarak gösterilebilir.

Okul dış1 öğrenme; okulun dışında gerçekleşen ve gönüllülük ilkesi gözetilerek yapılan bir öğrenme şekli olmakla birlikte bu ortamlarda Dewey'in yaparak-yaşayarak öğrenmesi kendini göstermektedir (Şen, 2019). Okul dışı öğrenme okul dışında deneyime dayalı olarak gerçekleştirilen bir öğrenme çeşididir (Holm, 2017). Öğrenci bu ortamlarda bilgiyi kendisi keşfetmekte, yorumlamakta ve nihayetinde bilgiyi yapılandırmaktadır. Sınıf içerisinde yapılan dersin çoğunluğu teoriktir ancak; okul dişı öğrenme ortamları öğrencilerin görerek, dinleyerek, dokunarak çeșitli etkinlikleri gerçekleștirildiği yerlerdir. Okul dıșı öğrenme ortamlarında yapılan eğitimlerin öğrencilerin bilişsel, duyuşsal ve devinişsel alanlarına pozitif etkisi olmaktadır (Şen, 2019).

Literatür incelendiğinde okul dışı öğrenme ortamları ile ilgili birçok çalışmaya rastlanmıştır ve şu şekildedir:

$\mathrm{Bu}$ yönde yapılan araştırmalardan elde edilen sonuçlara göre; ODÖO'nın öğrencilerin sosyal bilgiler dersi kazanımlarının verilebileceği uygun bir ortam olduğu (Topçu, 2017), bu ortamlarda; öğrencilerin gerçek yaşamla karşı karşıya kaldığı (Armağan, 2015), bireysel yetenekleri, öğrenci başarısını arttırdığı (Kaya, 2020; Ok ve Aslan, 2020), öğrencinin dikkatini çektiği bilhassa dikkati zayıf öğrencilerin konuya odaklanmasına yardımcı olduğu (Özdemir, 2019) ve bilginin uzun süre unutulmadığ Karamustafaoğlu, Karamustafaoğu ve Yapıcı, 2018; Karamustafaoğlu ve Ermiş, 2020; Kaya, 2020). Yapılan bir araştırmada non-formal ortamlara yapılan gezilerin bilginin kalıcılığ üzerine olumlu bir etkisinin olduğu sonucuna varılmıştır (Kaya, 2020). Ayrıca yapılan bir araştırmada “Okul dışı öğrenme deyince aklınıza ne geliyor?" sorusuna müze, tarihi yer, doğal yerler, okul bahçesi, kurum yerleri olduğu, okul dışı öğrenme ortamlarının öğrenmeyi desteklediği ortaya çıkmıştır (Armağan, 2015; Topçu, 2017). Yapılan başka araştırmalarda öğrencilerin; okul dış1 öğrenme ortamlarının öğrencilerin duyusal özelliklerine olumlu yönde katkısının olduğu, öğrenci motivasyonunu arttırdığı (Özdemir, 2019; Karamustafaoğlu ve Ermiş, 2020; Ok ve Aslan, 2020), öğrenilen bilgilerin daha kalıcı olduğu (Özdemir, 2019), konuları daha iyi kavrattığ 1 , bilimsel süreç becerilerini geliştirdiği, öğrencilerin ilgisini çektiği, bilişsel, duyuşsal ve fiziksel yönden öğrencileri geliştirdiği sonucuna varılmıştır (Kiriktaş ve Eslek, 2017; Yıldırım, 2018). Diğer bir araştırmada okul dışı ortamlarda yapılan STEM aktivitelerinin, öğrenciler üzerinde STEM alanındaki kariyer bilincinin gelişmesine pozitif etkisinin olduğu, öğrencilerin ilgisini çektiği, öğrencilerin uygulamada mutlu olduğu, işbirliğini, problem çözme becerisini, yaratıcı düşünmeyi geliştirdiği sonucuna varılmıştır (Altan, Üçüncüoğlu ve Öztürk, 2019). Ancak; yapılan diğer bir araştımada katılımcılar okul dışı öğrenmeler için ekonomik sebepler, hazırlıksızlık, izinlerin alınması, öğrenci sayısının çok olması, öğrencilerin güvenli 
yolculuğu gibi nedenlerle bu ortamlara gitmeyi zorlaştırdığı sonucuna varılmıştır (Topçu, 2017). Okullar, müze gezisine bürokratik işlemlerin fazlalığ 1 nedeniyle sıcak bakmamaktadır (Kartal ve Şeyihoğlu, 2020). Araştırma konusuyla ilgili literature taraması yapılmış ancak; aynı konuya sahip bir çalışmaya rastlanmamıştır. MEB' in 2023 Vizyonun' da ODÖO'nın öneminden bahsetmesi ile bu ortamları önemsediğinin kanıtıdır. Böylece yapılan bu çalışmanın literature katkı sağlayacağı düşünülmeltedir.

Bu çalışmanın problem cümlesi; ilkokul 3. sınıf hayat bilgisi dersi "Doğada Hayat" ünitesinde okul dışı öğrenme ortamlarının kullanımına yönelik sınıf öğretmenlerinin görüşlerini nelerdir?

\section{Araştırmanın Amacı}

Bu çalışmanın amacı: ilkokul 3. sınıf hayat bilgisi dersi "Doğada Hayat" ünitesinde okul dışı öğrenme ortamlarının kullanımına yönelik sınıf öğretmenlerinin görüşlerini belirlemektir.

\section{YÖNTEM}

$\mathrm{Bu}$ çalışmada amaç; sınıfını okul dışı öğrenme ortamlarına götüren sınıf öğretmenlerinin konuyla ilgili düşüncelerini belirlemektir. Araştırmacılar tarafından yöntem olarak; sınıfını son beş yılda okul dışı öğrenme ortamına götüren sınıf öğeretmenlerinin bu uygulamaya dönük düşünceleri araştırıldığından betimsel araştırma kullanılmıştır. Betimsel araştırma; Evrende yetenekler, inançlar, görüşler ve/veya bilgi gibi özellikleri tespit etmek için verilerin toplanmasıdır (Selçuk, 2019). Betimsel çalışmada örneklemin tutum, görüş, davranış ya da özellikleri betimlenir (Creswell, 2012; akt. Selçuk, 2019).

\section{Katılimcilar}

$\mathrm{Bu}$ çalışmada katılımcılar amaçlı örnekleme yöntemi içerisinde bulunan ölçüt örneklem yöntemi kullanılarak belirlenmiştir. Amaçlı örnekleme yöntemi araştırmada cevap aranan sorulara yanıt olacak zengin durumlara odaklanmaktadır (Bilici, 2019). Ölçüt örnekleme yöntemi araştırmada belli ölçütleri karşılayan bireylerin seçilmesidir (Bilici, 2019). Örneklemi oluşturacak katılımcılar belirlenirken ölçüt olarak kamuda çalışan son beş yılda sınıfını en az bir defa müze, hayvanat bahçesi, oyun parkı gibi okul dışı öğrenme ortamlarına geziyen götüren sınıf öğretmenlerine dikkat edilmiştir. Sivas İlinin Yıldızeli ilçesinde bulunan sınıf öğretmenlerine dönük yapılan bu çalışmada, bir öğretmen sınıfını bir gezi etkinliğine götürmek istediğinde öncelikle okul idaresinden izin alması gerektiği ve bu idare de bilgi amaçlı bağlı olduğu Milli Eğitim Müdürlüğüne bildirmesi gerektiği göz önüne alınarak gerekli bilgiler bu Milli Eğitim Müdürlügünden sağlanmıştır. Ardından 10 katılımcı belirlenmiştir. Katılımcıların demografik durumu tablo 1 'de verilmiştir. 
Tablo 1. Katılımcıların Demografik Bilgisi

\begin{tabular}{|c|c|c|}
\hline Cinsiyet & $\mathrm{F}$ & $\%$ \\
\hline Erkek & 2 & 20 \\
\hline Kadın & 8 & 80 \\
\hline \multicolumn{3}{|l|}{ Görev Yapılan Yer } \\
\hline İlçe Merkezi & 3 & 30 \\
\hline Köy & 7 & 70 \\
\hline \multicolumn{3}{|l|}{ Katılımcıların Hizmet Süresi } \\
\hline $1-5$ Y11 & 1 & 10 \\
\hline 5-10 Y1l & 7 & 70 \\
\hline $10-15$ Yil & 1 & 10 \\
\hline 15 Yıl ve üstü & 1 & 10 \\
\hline \multicolumn{3}{|l|}{ Okul Türü } \\
\hline Birleştirilmiş Sınıflı İlkokul & 6 & 60 \\
\hline Müstakil Sınıflı İlkokul & 4 & 40 \\
\hline \multicolumn{3}{|c|}{ Okul dıșı öğrenme ortamları ile İlgili Eğitim Alma Durumu } \\
\hline Evet & 0 & 0 \\
\hline Hayır & 10 & 100 \\
\hline \multicolumn{3}{|c|}{ Sınıfını Okul Dışı Ortama Götürme Sıklı̆̆ı $(2018,2019)$} \\
\hline 1 ya da 2 & 4 & 40 \\
\hline 5 ya da 6 & 3 & 30 \\
\hline 7 ve üstü & 3 & 30 \\
\hline
\end{tabular}

Tablo 1 incelendiğinde katılımcıların hiçbirinin okul dışı ortamlarla ilgili eğitim almadığı tespit edilmiştir.

\section{Veri Toplama Araçları}

$\mathrm{Bu}$ çalışmada veri toplama aracı olarak yarı yapılandırılmış görüşme sorularının olduğu form kullanılmıştır. Görüşme belli bir konu ile ilgili iki kişi ve daha fazla bireyle yapılan ve sözlü olarak gerçekleştirilen iletişim sürecidir (Aktaş, 2019). Yarı yapılandırılmış görüşmelerde araştırmanın hedefi doğrultusunda bilgiler elde etmek maksadıyla birtakım soruların oluşturduğu görüşme formundan yararlanılmakta ve bu form sayesinde elde edilen bilgiler çerçevesinde bilgiler arasındaki benzerlik ile farklılıklar tespit edilmektedir (Aktaş, 2019). Konu ile ilgili alanyazın taraması yapılıp alanında uzman iki öğretim üyesinin de görüşleri alınarak görüşme formu oluşturulmuştur (Ek). Form soruların anlaşırlığı ile ilgili sınıf öğretmenine okutulduktan sonra nihai hali verilmiştir. Araştırmacılar tarafından örneklem belirlendikten sonra araştırma izni ile okul müdürlüklerinden görüşme isteğinde bulunmuştur. $\mathrm{Bu}$ şekilde toplam 10 öğretmen ile birer kez yüz yüze görüşme gerçekleştirilmiş olmakla beraber her bir görüşme yaklaşık olarak $30 \mathrm{dk}$ sürmüştür. Araştırma 2019 öğretim yılının sonbahar döneminde gerçekleştirilmiştir.

\section{Verilerin Analizi}

$\mathrm{Bu}$ çalışmada nitel verilerin analiz edilmesinde yararlanılan betimsel analiz tekniği kullanılmıştır. Betimsel analiz daha önceden tespit edilen kategori veya boyutlar göz önüne alınarak veriler özetlenir ve yorumlanır, temalar haricinde olan veriler dikkate alınmaz (Akbulut, 2012). Araştırmacılar tarafından ilgili alanyazın gözden geçirilip katılımcıların yanıtları da incelendikten sonra betimsel analiz için temalar belirlenmiştir. Ardından alanında uzman iki öğretim üyesine temalar gösterilmiş ve bunlara son hali verilmiştir. Öğretmenlerin okul dışı öğretime dair düşünceleri şu temalar çerçevesinde kodlanmıştır: 
"Okul Dışı Öğrenme Ortamlarının (ODÖO) faydaları", ODÖO tamamlayıcı", "Etkili ODÖO” "Disipliner bağlantılar", ODÖO’rında hazırlık süreci”, “ODÖO’nda riskler” ODÖO’da uygulama süreci” şeklindedir.

Ayrıca katılımcılar "K" harfi ile gösterilmiştir. Örneğin birinci katılımcı "K1" şeklinde ifade edilmiştir.

\section{Geçerlilik ve Güvenirlik}

Bir çalışmada geçerlilik; araştırmacının elde ettiği verileri ayrıntılı olarak açıklaması, araştırmacının sonuçları nasıl elde ettiğini anlatması, katılımcıların görüşlerine doğrudan alıntılar şeklinde yer vermesidir (Yıldırım ve Şimşek, 2018). Bu çalışmada tüm katılımcılarla yüz yüze görüşmeye geçilmeden önce kısa bir sohbet yapılmış, sonrasında tüm katılımcılarla yüz yüze görüşme gerçekleştirilmiştir. Sorular sorulup cevaplar alındıktan sonra yanıtlar değiştirilmeden araştırmacılar tarafından forma yazılmıştır. Her bir katılımcı ile yaklaşık olarak $30 \mathrm{dk}$ ve birere kez görüşme yapılmıştır. Güvenirlikte; nitel araştırmada güvenirlik gerçeklerin bireylere ve ortama göre değiştiği, araştırmanın benzer gruplara tekrarlandığında benzer neticelere ulaşmanın mümkün olmadığı, aynı verilerin iki araştırmacı tarafından farklı yorumlanabileceği göz ardı edilememektedir (Yıldırım ve Şimşek, 2018). Görüşme ile gelen veriler alanında uzman iki öğretim üyesine gösterilmiş ve onların birlikte mutabık oldukları temalar, çözümlemeler araştırmada yerini almıştır.

\section{BULGULAR}

Bu çalışmada ilkokul 3. sınıf hayat bilgisi dersi "Doğada Hayat" ünitesinde okul dışı öğrenme ortamlarının kullanımına yönelik sınıf öğretmenlerinin görüşleri incelenmiştir. Katılımcıların araştırma sorusuna yönelik verdiği yanıtlar Tablo 2'de verilmiştir.

Tablo 2. Katılımcıların Hayat Bilgisi Dersinin Okul D1şı Ortamlarda Öğretilmesi ile ilgili görüşleri

\begin{tabular}{|c|c|c|c|c|}
\hline Sira & Temalar & Doğrudan Alıntılar & $\mathbf{f}$ & $\%$ \\
\hline 1 & $\begin{array}{l}\text { "ODÖO’nın } \\
\text { faydaları" }\end{array}$ & $\begin{array}{l}\text { "Evet faydalı olduğunu düşünüyorum. Doğada Hayat Ünitesinin" } \\
\text { kazanımlarını öğrencilerin yaparak yaşayarak öğrenmesine katkı sağlar." } \\
\text { (K 1) } \\
\text { "2. sınıf öğretmeniyim ama 2. sınıf Hayat Bilgisi ünitelerinde de "Doğada } \\
\text { Hayat" var. Okul dışı ortamlarda bu kazanımlar verilmelidir. Gerçek } \\
\text { öğrenme ortamlarında çok daha kalıcı ve derinlemesine bir eğitim söz } \\
\text { konusudur.” (K8) "Evet vardır. Öğrenci resimlerden, videolardan ya da } \\
\text { yazılardan öğrenmek yerine dokunarak, tadarak, hissederek öğrenirse bu } \\
\text { tam öğrenme olur. Biz okul ortamında çocuklara en fazla gülü öğretiriz } \\
\text { ama gülün nasıl koktuğunu koklamadan bilemezler" (K8) } \\
\text { Öğrenmelerin yaparak yaşayarak gerçekleştirilen uygulamalarda daha } \\
\text { kalıcı olduğu bilinmektedir. Özellikle Hayat Bilgisi dersi konuları } \\
\text { itibariyle günlük yaşamı içermekteidr. Bu sebeple Hayat Bilgisi dersinde } \\
\text { ODÖO’nın kullanılması öğrenciler için faydalı olmaktadır...Öğrencilerin } \\
\text { bitkilere dokunması ve yaşam ortamlarını görmeleri gerekir. Hayvanların } \\
\text { insanlar için önemini fark etmeleri, insanların hayatındaki yerini bilmeleri } \\
\text { içişn en etkili yöntem okul dışı etkinliklerdir. Çevreyi keşfedebilmeleri } \\
\text { ancak çevrenin ve doğanın içinde bulunarak mümkün olabilmektedir." } \\
\text { (K5) }\end{array}$ & 10 & 100 \\
\hline
\end{tabular}

2 "ODÖO tamamlayıcı"
“...Okul içi ve okul dışı öğrenme birbirini desteklemelidir. Fakat 8 okullarda yeteri kadar öğrenmeyi destekleyen araç-gereç belki atolye tarsi ortamların da olması gereklidir" (K 4) 
"Disipliner bağlantılar"
"Hayat Bilgisi dersi "Doğada Hayat" ünitesi kazanımlarına bakıldığında öğrenciler için ön bilgiler gereklidir. Konular hakkında teorik bilgi olmadan uygulamaların yapılması hedeflenen öğrenmeyi gerçekleştirmede yetersiz kalabilir. Örneğin ünitede yer alan yön bulma konusunda Doğadan yararlanarak yönleri bulur." kazanımı bulunmaktadır. Doğada yön bulma yöntemleri olan Güneş'in, karınca yuvalarının ve ağaçları yosun tutan kısımlarının yön bulmada yararlandığımız yöntemler olduklarını önceden bilmeleri gerekir. Çünkü doğaya gidildiğinde nelere bakarak yönlerini bulabileceklerini öğrendikleri bilgilere bakarak anlayabilecekleridr. (K 5)

"Yeterli olmayabilir. Teoride kalan genel bilgilerle desteklenebilir. Ayrıca doğada elde edilen çıktıların yorumlanıp sonuna bağlanması, fikir alışverişinde bulunup beyin firtınasıyla öğrenmelerin değerlendirilmesi gerekir." (K10)

"Doğal sit alanları ve ören yerleri, bilim merkezleri gibi ODÖO'nın daha 8 etkili olduğunu düşünüyorum. Çünkü bu öğrenme ortamlarında bitki ve hayvan gözlemleme, güneş, ay ve yıldızları araştırabilmesine daha uygun ortamlar oluşturulmalıdır. Botanik bahçeleri, hayvanat bahçelerini de ekleyebilirsizniz." (K 6)

" Gezi, gözlem, inceleme için park, orman hayvanat bahçesi gibi doğal ortamlar etkilidir" (K 8)

"3. sınıf Hayat Bilgisi dersi "Doğada Hayat" ünitesindeki konuları için pek çok ODÖO bulunmaktadır. "Bitki ve Hayvanlar" konusu için ögrencilerle birlikte hayvanat bahçesine gidilebilir. Çevre koşullarına göre hayvanların buluduğu uygun alanlara gidilebilir. Yine çevreye bakıldığında birçok bitki çeşidi bulunmaktadır. En yakından başlanarak çevredeki bitkiler incelenebilir. "Meyve ve Sebze Yetiştiriciliği” konusu için öncelikli olarak bahçeleri bulunan öğrencilerin bahçelerine gidilebilir. Orada öğrencinin arkadaşlarına bilgi vermesi akran öğretimi ile öğrenmeyi sağlar. Yrıca firsat eşitliği sağlanarak kalıcı öğrenme sağlanmış olur. Yönleri bulma konusunda öğrencileri okula yakın bir alanda öğrendiklerini uygulama firsatı verilebilir. Bir karınca yuvası bulunarak yönün nasıl belirlendiği uygulayarak gösterilebilir. Öncelikli olarak öğrencinin yakın çevresinden başlayarak çevrenin değişimi üzerine incelemelerde bulunulabilir. İnsanların çevreye etkisi ile nelerin değiştiği gözlemlenir. Olumlu ve olumsuz değişimler üzerinde durulur. Olumsuz etkilerin nasıl azaltılabileceği yine uygulamalarla anlatılabilir. Örneğin çevrenin temiz tutulması için insanların bilinçlendirilmesi gerektiği anlatılır. Ağaç dikilmesinin öneminden bahsedilir. Öğrencilerle birlikte yakın çevreden başlanarak ağaç dikimi gerçekleştirilebilir...” (K5)

"Fen Bilimleri dersine daha çok katkısı olur. Çünkü konular birbirine 10 daha yakın. Kazanımları ODÖO'na daha uygundur. Bu yerlerde Fen Bilimleri dersinin işlenmesinde daha eğlenceli, daha etkili öğrenme olacağını düşünüyorum. Bir de öğrenci öğrendiğini unutmayacaktır.” (K 7)

“ODÖO’nın tüm derslere katkı sağlayacağı düşünmekle birlikte "Doğada Hayat" ünitesinin okul dışında verilmesinin en çok Fen Bilimleri dersine katkı sağlayacağını düşünüyorum. Çünkü 3. sınıf Fen Bilimleri dersinde "Canlılar Dünyasına Yolculuk" gibi "Doğada Hayat" ünitesiyle ilişkilendirilecek üniteler mevcut." (K1)

“3. sınıf Hayat Bilgisi dersi “Doğada Hayat" ünitesinin ODÖO'ında verilmesi daha çok Fen Bilimleri dersine katkıda bulunmaktadır. Fen Bilimleri dersinde "Canlılar Dünyası" ünitesi ile Hayat Bilgisi dersi "Doğada Hayat" ünitesinde yer alan konular birbirine benzemektedir. İki unite birbirini tamamlamaktadır. Disiplinler arası ilişkilendirme ile Hayat Bilgisi dersi Fen Bilimleri dersine katkı sağlamaktadır.” (K5) 
A. KARBEYAZ \&

M. KURT

5 "ODÖO'rında hazırlık süreci"

6

“ODÖO’nda riskler"

“ODÖO'da uygulama süreci”'

"Fen Bilimleri dersine daha faydalı olacaktır. Çünkü Hayat Bilgisi dersi ile paralellik gösterdiği konular daha fazladır.” (K 3 )

"Amaca hizmet etmesine, öğrenciyi sürece dâhil etmeye dikkat 10 edilmelidir. Maddi imkânları zorlamadan ulaşılabilecek güvenli ortamlar seçilmelidir. Kalabalık sınıflarda güvenliği sağlama kaygısı verimliliği düşürebilir..." (K 10)

"Öncelikle çocukların güvenliğine dikkat edilmesi gerekir. Güvenlik her şeyden önemlidir...”, K 8: Sınıf dışı etkinliklerin çocukların dikkatini konuya odaklamak daha zor olması bir problemdir. Ayrıca güvenlik sorunları ortaya çıkar.” (K 2)

"Öğretmen uygun içeriğin nasıl bir ortamda, hangi yöntemi kullanarak öğreteceğini önceden planlamış, kendi rolünü benimsemiş ve öğretim sürecini tasarlamış olması gerekmektedir. $\mathrm{Bu}$ sebeple öğretmenlerin ODÖO ile ilgili yeterli bilgi düzeyine sahip olmaları gerekmektedir. Aksi takdirde öğrenme başarılı olamayacaktır.” (K6)

"Kalabalık sınıflarda dersi işleme verimli olmaz. Öğrencilerin derse odaklanmasını güçleştirebilir. Çünkü her kafadan bir ses yükselir. Doğada uyarıcıların fazla olması dikkat dağınıklığı yaratabilir.” (K 10)

"Dikkat süreleri kısa olduğu için farklı uyaranlara odaklanıp hedeften uzaklaşabilirler.” (K 3)

"Kalabalık sınıflarda güvenliği sağlama kaygısı verimliliği düşürebilir. Doğada uyarıcıların fazla olması dikkat dağınıklığı yaratabilir." (K 10) "Sinif dişı etkinliklerin çocukların dikkatini konuya odaklamak bir problemdir. Ayrıca çocuklar fiziksel ihtiyaçları konusu ve güvenlik sorunları ortaya çıkar.” (K8)
"Öğrenci gruplarının sayıları az olabilir, çevreden ya da velilerden
"Bunlarin çözümü için müfredatın zamana uyarlanması gerekir. Daha çok vakit ayrılmalıdır. MEB'in buna yönelik bütçe oluşturması gerekir. Güvenlik sorunları için çocukları yanına fazladan öğretmen verilebilir. Ya da görevli kişiler verilebilir. ODÖO'larında güvenliğin de sağlanması gerekir." (K7)
"Okul dışı öğrenme yapmaya karar verildiği takdirde iyi bir planlama yapılması gerekmektedir. Bütün tedbirler alınmalı, öğrenciler bilgilendirilmelidir. Öğrencilerde sağlık problem olanlar (alerji, devamlı ilaç kullanma gibi) tespit edilmelidir." (K 2)
“ODÖO'na çıkılmadan önce öğrencilerin gerekli disiplin kurallarını uygulayabileceklerinden emin olmak gerekir. Bunun için önceden sınıfta bu konu hakkında bilgi verilmelidir. Gidilecek yerlerde kurallara uyulmadığında hangi olumsuzlukların yaşanabileceği anlatılmalıdır. Bu konuda dikkat edilmesi gereken öğrenciler gözlem altında tutulmalıdır." (K5)

Tablo 2.'de sunulan veriler incelendiğinde örneklem grubunu oluşturan öğretmenlerin şu yönde görüşler belirttiği görülmektedir;

3.sınıf Hayat Bilgisi dersi “Doğada Hayat Ünitesi” nin ODÖO’nda verilmesinin yaparak yaşayarak öğrenmeye faydasının olduğu,

3. sınıf Hayat Bilgisi dersi "Doğada Hayat Ünitesi” kazanımlarının ODÖO’ında verilmesi, sınıfta yapılan faaliyetlerin tamamlayıcısı olduğu,

3.sınıf Hayat Bilgisi dersi "Doğada Hayat Ünitesi” kazanımlarının doğal alanlar ve hayvanat bahçesinde işlenmesinin diğer ODÖO’ına nazaran daha faydalı olduğu, 
3.sınıf Hayat Bilgisi dersi "Doğada Hayat Ünitesi” kazanımlarının ODÖO’nda verilmesinde özellikle fen bilimleri dersine katkısının daha fazla olduğu,

3.sınıf Hayat Bilgisi dersi “Doğada Hayat Ünitesi” nin ODÖO’nda verilmesine yönelik en fazla ODÖO’nda güvenliğe dikkat edilmesi gerektiği,

3.sınıf Hayat Bilgisi dersi "Doğada Hayat Ünitesi" nin ODÖO’nda verilmesinde öğrenci dikkatinin dağılması ve öğrenci güvenliğine dikkat edilmesi gerektiği,

3.sınıf Hayat Bilgisi dersi "Doğada Hayat Ünitesi” nin ODÖO'nda işenmesinde ortaya çıkabilecek problemlerin önceden iyi bir planlama yapılmalısı ile üstesinden gelinebileceği yanıtları verilmiştir.

Araştırmadan gelen bulgular yorumlandığında; ODÖO’nda gerçekleştirilen etkinliklerin öğrencilerin yaparak yaşayarak deneyim kazanmasını sağladığı ve bu şekilde bilginin daha kalıcı olduğu, okul dışı ortamlarda gerçekleştirilen etkinliklerin tek başına konuların kavratılmasında yeterli olamayacağı teorik bilgi ile desteklenmesi gerektiği, katılımcılar tarafından en çok "Doğal Ortamlar ve Hayvanat Bahçelerinin" ODÖO olarak bilindiği, Hayat Bilgisi dersi "Doğada Hayat" ünitesi kazanımlarının ODÖO'nda verilmesinin en çok Fen Bilimleri dersi kazanımlarına katkı sağladığı, bu ortamlarda en fazla öğrencilerin güvenlik önlemlerinin alınması gerektiği ve dikkatlerinin dağıtılmamasına önem gösterilmesi gerektiğgi, bu sorunların iyi bir planlamanı yapılması ile üstesinden gelinebileceği ortaya çıkmıştır.

\section{SONUÇ VE ÖNERİLER}

\section{Sonuçlar}

Çalışmanın birinci sorusu; “3. sınıf Hayat Bilgisi dersi “Doğada Hayat Ünitesi” nin ODÖO’nda verilmesinin öğrenci açısından sizce faydası var mıdır? Neden?" şeklindedir. Katılımcıların yanıtları incelendiğinde; ODÖO’nda gerçekleştirilen etkinliklerin öğrencilerin yaparak yaşayarak öğrenmelerine firsat verdiği, bilgiyi kendilerinin yapılandırdığı, öğrendikleri konuların daha kalıcı olduğu sonucuna varılmıştır. Elde edilen bu sonuçlar alanyazında mevcut birçok çalışma ile de paralellik göstermektedir. Öğrenciler okul dişında yaparak yaşayarak öğrenmekte, bu ortamlar onların dikkatini çekmekte, öğrenme isteyerek gerçekleşmekte ve öğrenilen bilgiler daha kalıcı olmaktadır (Keskin ve Rennie, Feher, Dierking ve Falk, 2003; Kaplan, 2012; Kardemir, 2013; Armağan, 2015; Sonay, Tutar ve Karamustafaoğlu, 2016; Kiriktaş ve Eslek, 2017; Sarığlan ve Küçüközer, 2017; Topçu, 2017; Bakioğlu, Karamustafaoğlu, Karamustafaoğu ve Yapıc1, 2018; Çebi, 2018; Gürsoy, 2018; Yıldırım, 2018; Altan, Üçüncüoğlu ve Öztürk, 2019; Can, 2019). Ancak Tablo 1'de katılımcıların çoğunluğu Köy'de görev yapması öğrencilerini ODÖO’na götürmeyi biraz daha zorlaştırabilmektedir ki öğrenci velilerinin maddi durumlarının yetersiz olması yüksek muhtemeldir. Bu da firsat eşitliği noktasinda problemlere neden olabilir.

Çalışmanın ikinci sorusu; "Sizce Hayat Bilgisi dersi "Doğada Hayat Ünitesi” nin kazanımlarının sadece ODÖO'nda yapılması yeterli midir?" şeklindedir. Katılımcıların yanıtları incelendiğinde; Hayat Bilgisi dersi "Doğada Hayat" ünitesinin sadece ODÖO'nda yapılması yeterli olmadığı sonucu elde edilmiştir. Çünkü öğrenciler öncelikle teorik bilgiyle donatılıp sonrasında bu etkinliklere götürülebilir. Sadece uygulamalı etkinlikler yetmemekte ayrıca teorik bilgi de gerekmektedir (Topçu, 2017). 
Çalışmanın üçüncü sorusu; “3. sınıf Hayat Bilgisi dersi “Doğada Hayat Ünitesi” nin ODÖO’nda verilmesinde hangi tür ODÖO’nda daha etkilidir? Neden?” Katılımcıların yanıtları incelendiğinde; katılımcılar "Doğada Hayat" ünitesinin "Doğal Ortamlarda ve Hayvanat Bahçeleri” nde verilmesinin daha etkili olabileceğini ifade etmiştir. Fen Bilgisi dersi için en uygun ODÖO "Doğal Alanlar ve Hayvanat Bahçeleri” dir (Gürsoy, 2018). Buna karşın ODÖO olarak katılımcılar en az park, doğal yerler, müze olarak belirtilmiştir (Sarığlan ve Küçüközer, 2017). Bu durum araştırmanın yapıldığı bölgedeki ODÖO'nın varlığından ya da katılımcıların konu ile ilgili yeterince bilgilerinin olmamasından kaynaklanabilir. Tablo 1 incelendiğinde katılımcılardan hiçbirinin okul dışı öğrenme ortamları ile ilgili bir eğitim almadıkları görülmektedir.

Çalışmanın dördüncü sorusu; "3. sınıf Hayat Bilgisi dersi "Doğada Hayat Ünitesi” nin ODÖO'nda verilmesinde özellikle hangi derse daha fazla katkısı olmaktadır? Neden?" Katılımcıların yanıtları incelendiğinde; “Doğada Hayat" ünitesi kazanımlarının ODÖO’nda verilmesinin özellikle Fen Bilimleri dersi kazanımlarının öğrenilmesini sonucuna varılmıştır.

Çalışmanın beşinci sorusu; “3. sınıf Hayat Bilgisi dersi “Doğada Hayat Ünitesi” nin ODÖO’nda verilmesine yönelik en fazla nelere dikkat edilmelidir? Neden?" Katılımcıların yanıtları incelendiğinde; bir etkinliğin ODÖO'nda gerçekleştirilmesinde güvenlik tedbirlerinin alınması ve öğrenci dikkatini dağıtacak etkenlerin önemsenmesi gerektiğgi sonucuna varılmıştır. ODÖO'nda özellikle öğrencilerin kontrollerini sağlamak zordur (Sarıoğlan ve Küçüközer, 2017).

Çalışmanın altıncı sorusu; “3. sınıf Hayat Bilgisi dersi “Doğada Hayat Ünitesi” nin ODÖO’nda verilmesinde hangi problemlerin ortaya çıkması yüksek olasılıktadır? Neden?” Katılımcıların yanıtları incelendiğinde; ODÖO'a yapılan gezilerde güvenlik ve öğrenci izinlerinin alınmasının problemlerin ortaya çıkabileceği sonucuna varılmıştır. Gezi ile ilgili öğrenci izin ve güvenliği problem olarak görülebilir (Topçu, 2017). Katılımcılar ODÖO'nda gerçekleştirilen faaliyetlerin iyi bir planlama yapılması ile ortaya çıkabilecek olumsuzlukların en aza indirilebileceğini ifade etmiştir ama; Tablo 1 incelendiğinde katılımcıların ODÖO ile ilgili hiçbir eğitim almadıkları görülmüştür. Bu da iyi bir planlamanın gerçekleştirilmesinin önüne engel olarak görülebilir.

Çalışmanın yedinci sorusu “3. sınıf Hayat Bilgisi dersi "Doğada Hayat Ünitesi” nin ODÖO’nda verilmesinde ortaya çıkması yüksek olasılıktaki problemlere yönelik çözüm öneriniz nelerdir?" şeklindedir. Katılımcıların yanıtları incelendiğinde; geziye çıkılmadan once iyi bir planlama yapılması ile ortaya çıkabilecek problemlerin en aza indirilebileceği sonucuna varılmıştır. Gezinin iyi bir şekilde gerçekleşmesi için öncelikle iyi bir planlama yapılmalı ve sonrasında gezi ile ilgili öğrencilere hayati sorular sorulup onların kazandıkları muhtemel bilgiler sorgulanmalıdır (Uitto, Juuti, Lavonen, \& Meisalo, 2006; Keskin ve Kaplan, 2012).

$\mathrm{Bu}$ çalışmadan gelen veriler çerçevesinde; ODÖO'nın öğrencilerin yaparak-yaşayarak bilgiyi ilk elden kazandırdığı ve bunun neticesi olarak da öğrenilen bilginin daha kalıcı olduğu sonucuna varılmıştır, Ancak eğitimin sadece ODÖO’nda gerçekleştirilmesinin tek başına konuların kavratılmasında yeterli olamayacağı bunun sınıfta verilen teorik bilgi ile desteklenmesi gerektiği sonucu elde edilmiştir. Ayrıca katılımcıların gezi öncesi, gezi anı ve gezi sonrası uygulamalarında yeterince bilgilerinin olmaması onların ODÖO ile ilgili bir eğitim almadıklarından kaynaklandığı sonucuna varılabilmektedir. 


\section{Öneriler}

$\mathrm{Bu}$ çalışmada elde edilen sonuçlar ışığında aşağıda bulunan öneriler getirilebilir:

1. Derslerin kazanımları baz alınarak öğretmenler okul dışı öğrenme ortamlarına gitmeden öncesi, gezi anını ve gezi sonrasını nasıl verimli geçirebilecekleri konusunda eğitimler verilip, sonrsında sinava tabi tutularak sinavi geçen öğretmenlerin gezi masraflari karşılanabilir.

2. Okul dışı öğrenme ortamlarında bulunan rehberlere pedagojik eğitimler verilebilir.

3. Okul dışı ortamlar öğrenmeyi kolaylaştırması bakımından uzman görüşleri doğrultusunda yeniden dizayn edilebilir.

4. Okul bahçesi uygun olan sınıflar bu üniteyi bahçede işleyebilir.

5. Tüm derslerin uygun olan kazanımları okul dışı öğrenme ortamlarında işlenebilir.

6. Bu çalışma literature sınıf öğretmenlerinin hayat bilgisi dersi için görüşlerini sunmuştur. Bu yönde çalışma yapacak diğer araştırmacılar farklı branşlardan örneklem grubu alarak farklı derslerden çalışabilir.

\section{KAYNAKÇA}

Akbulut, Y. (2012). Sosyal bilimlerde araştırma yöntemleri (Ed. Ali Şimşek). Sosyal bilimlerde araştırma yöntemleri. Eskişehir: Anadolu Üniversitesi Yayınları.

Aktaş, M. C. (2019). Nitel veri toplama teknikleri (Ed. Haluk Özmen ve Orhan Karamustafaoğlu, 2019). Eğitimde araştırma yöntemleri (114-135). Ankara: Pegem Yayınları.

Altan, E. B. Üçüncüoğlu, İ. ve Öztürk, N. (2019). Preparation of out-of-school learning environment based on science, technology, engineering, and mathematics education and investigating its effects. Science Education International, 30(2), 138-148.

Armağan, B. (2015). Illkokul 4. sinıf fen öğretiminde okul dışı öğrenme ortamları: bir eylem araşstırması (Yüksek Lisans Tezi). Dokuz Eylül Üniversitesi, Eğitim Bilimleri Enstitüsü, İlköğretim Anabilim Dalı, Sınıf Öğretmenliği Programı, İzmir.

Bakioğlu, B., Karamustafaoğlu, Karamustafaoğu, O. ve Yapıcı, Ş. (2018) . The effects of out-of-school learning settings science activities on 5th graders' academic achievement. European Journal of Educational Research, 7(3), 451 - 464.

Baysal, Z. N., Tezcan, Ö. ve Araç, K. E. (2018). Türkiye ve Almanya-Hamburg hayat bilgisi dersinin karşılaştırılması: Genel bir bakış. Kuramsal Eğitimbilim Dergisi, 11(1), 117-134.

Bilici, S. C. (2019). Örnekleme yöntemleri (Ed. Haluk Özmen ve Orhan Karamustafaoğlu, 2019). Eğitimde araştırma yöntemleri. Ankara: Pegem Yayınları.

Can, N. S. (2019). Geri dönüşüm ve çevreye etkileri konusunda okul dışı ögrrenme ortamları etkinliklerinin ilkokul ögrencilerinde farklı değiş̧kenler açısından incelenmesi (Yüksek Lisans Tezi). Erzincan Binali Yıldırım Üniversitesi Sosyal Bilimler Enstitüsü İlköğretim Anabilim Dalı SınıfÖğretmenliği Bilim Dalı, Erzincan.

Claiborne, L., Morrel, J., Bandy, J. ve Bruff, D. (2019). Teaching outside the classroom. Bu kaynağa 14.12.2019 tarihinde https://cft.vanderbilt.edu/guides-sub-pages/teaching-outside-the-classroom/ internet adresinden ulaşılmuşıtır.

Çebi, H. (2018). Farklı okul dışı öğrenme ortamlarının, öğrencilerin fen bilimleri dersine karşı ilgi ve tutumlarına etkisi (Yüksek Lisans Tezi). Yıldız Teknik Üniversitesi Fen Bilimleri Enstitüsü, Matematik Ve Fen Bilimleri Eğitimi Anabilim Dalı Fen Bilgisi Öğretmenliği Programı, İstanbul.

Çepni, S. ve Ormancı, Ü. (2018). Geleceğin dünyası (Ed. Salih Çepni, 2018). Kuramdan uygulamaya STEM Eğitimi (4. Baski).Ankara: Pegem Yayıncılık.

Ertürk, S. (1988). Türkiye'de eğitim felsefesi sorunu. Hacettepe Üniversitesi Eğitim Fakültesi Dergisi, Sayı 3, 11 16. 
Gündoğan, A. Ve Gültekin, M. (2018). İlkokul 3. sınıf öğrencilerinin hayat bilgisi dersi "okul heyecanım" temasındaki kavramlara ilişkin bilişsel yapıları. Elektronik Sosyal Bilimler Dergisi, 17(65), 233-247.

Gürsoy, G. (2018). Fen öğretiminde okul dışı öğrenme ortamları. Turkish Studies, 13(11), 623-649.

Holm, T. (2017). Out of box - environmental outdoor education in Finland. Bu kaynağa 14.12.2019 tarihinde https://epale.ec.europa.eu/en/content/out-box-environmental-outdoor-education-finland adresinden ulaşılmıştır.

Kartal, A. ve Şeyihoğlu, A. (2020). Öğrenci bakış açısıyla sosyal bilgilerde okul dışı öğrenme ortamları bağlamında "Müzeler". Gazi Eğitim Bilimleri Dergisi, 6(1), 128-146.

Karamustafaoğlu, O. ve Ermiş, M. (2020). Biyoteknoloji konusunun okul dışı fen ortamında öğretimine yönelik öğrenci görüşleri. Eskişehir Osmangazi Üniversitesi Türk Dünyası Uygulama ve Araştırma Merkezi, 5(1), 92-114).

Kaya, D. M. (2020). Non-formal öğrenme ortamlarinin epizodik belleğe ve öğrenci başarisina etkisinin araştirilmasi: enerji parki (Yüksek Lisans Tezi). Hacettepe Üniversitesi Eğitim Bilimleri Enstitüsü, İlköğretim Ana Bilim Dalı İlköğretim Fen Bilgisi Eğitimi Programı, Ankara.

Kiriktaş, H. ve Eslek, S. (2017). The experience of assessing out-of-school learning environments. Universal Journal of Educational Research 5(8): 1410-1424.

Ok, Z. ve Aslan, O. (2020). Konya bilim merkezinde gerçekleştirilen atölye çalışmalarının ilkokul ve ortaokul öğrencileri tarafından değerlendirilmesi. Cumhuriyet International Journal of Education - Cumhuriyet Uluslararası Ĕ̈itim Dergisi, 9(1), 28-45.

Özdemir, L. A. (2019). Views of pre-service science teachers about informal learning environments before and after science and technology museum visit (graduate). The Graduate School Of Natural And Applied Sciences Of Middle East Technical University, Ankara.

Rennie, L. J., Feher, E., Dierking, L.D. ve Falk, J. H. (2003). Toward an agenda for advancing research on science learning in out-of-school settings. Journal Of Research In Sclence Teaching, 40(2), 112-120.

Sarığlan, A. B. ve Küçüközer, H. (2017). Fen bilgisi öğretmen adaylarının okul dışı öğrenme ortamları ile ilgili görüşlerinin araştırılması. Informal Ortamlarda Araştırmalar Dergisi (IAD), 2(1), 1-15.

Selçuk, G. S. (2019). Tarama yöntemi (Ed. Haluk Özmen ve Orhan Karamustafaoğlu, 2019). Eğitimde araştırma yöntemleri (140-161). Ankara: Pegem Yayınları.

Şen, A.İ. (2019). Okul dışı öğrenme nedir? (Ed. Ahmet İlhan Şen, 2019). Okul dışı öğrenme ortamları (2-18). Ankara: Pegem Yayınları.

Topçu, E. (2017). Out of school learning environments in social studies education: a phenomenological research with teacher candidates. International Education Studies; 10(20), ISSN 1913-9020 E-ISSN 1913-9039 Published by Canadian Center of Science and Education.

Uitto, A., Juuti, K., Lavonen, J. \& Meisalo, V. (2006). Students' interest in biology and their out-of-school experiences. Journal of Biological Education, 40(3), 124-129.

Yağc1, E. (1998). Demokrasi ve eğitim. Eğitim ve Bilirn, 22(107), 15 -22.

Yıldırım, A. ve Şimşek, H. (2018). Sosyal bilimlerde nitel araştırma yöntemleri (11. Baskl). Seçkin Yayıncılık: Ankara. 


\section{EK:}

\section{Yarı yapılandırılmış Görüşme Formu}

Bu çalışmanın amacı: İlkokul 3. sınıf hayat bilgisi dersi "Doğada Hayat" ünitesinde okul dışı öğrenme ortamlarının kullanımına yönelik sınıf öğretmenlerinin görüşlerinin belirlenmesi. Bu amaç doğrultusunda toplanan veriler sadece bilimsel amaçlı kullanılacak olup sizi belirtecek herhangi bir kişisel bilgi istenmeyecektir.

Aytekin KARBEYAZ

A Ü Sınıf Eğt. Dok. Öğrencisi

\section{Cinsiyetiniz}
a) Erkek
b) Kadın

\section{Görev Yaptığınız Yer}

a) İlçe Merkezi $\quad$ b) Belde $\quad$ c) Köy

\section{Hizmet Süresi}
a) $1-5$ y1l
b) $5-10$ y1
c) $10-15$ y1
d) 15 yıl ve üstü

\section{Görev Yaptığınız Okul Türü}

a) Birleştirilmiş Sınıflı $\quad$ b) Müstakil

\section{Okul Dışı Öğrenme Ortamı İle İlgili Bir Eğitim Aldınız mı?}

a) Evet b) Hayır

\section{Mesleğiniz boyunca sınıfınızı Okul Dışı}

Öğrenme Ortamına Götürme Sıklığı
a) 1-2
b) 3-4
c) $5-6$
d) 7 ve yukarı

\section{SORULAR}

1. 3.sınıf Hayat Bilgisi dersi "Doğada Hayat Ünitesi” nin okul dışı öğrenme ortamlarında verilmesinin sizce faydası var midır? Neden?

2. Sizce Hayat Bilgisi dersi "Doğada Hayat Ünitesi” nin kazanımlarının sadece okul dışında yapılması yeterli midir?

3. 3.sınıf Hayat Bilgisi dersi "Doğada Hayat Ünitesi" nin okul dışı öğrenme ortamlarında verilmesinde hangi tür okul dışı öğrenme ortamı daha etkilidir? Neden?

4. 3.sınıf Hayat Bilgisi dersi "Doğada Hayat Ünitesi" nin okul dışı öğrenme ortamlarında verilmesinde özellikle hangi derse daha fazla katkısı olmaktadır? Neden?

5. 3.sınıf Hayat Bilgisi dersi "Doğada Hayat Ünitesi” nin okul dışı öğrenme ortamlarında verilmesine yönelik en fazla nelere dikkat edilmelidir? Neden?

6. 3.sınıf Hayat Bilgisi dersi “Doğada Hayat Ünitesi” nin okul dışı öğrenme ortamlarında verilmesinde hangi problemlerin ortaya çıkması yüksek olasılıktadır? Neden?

7. 3.sınıf Hayat Bilgisi dersi "Doğada Hayat Ünitesi" nin okul dışı öğrenme ortamlarında verilmesinde ortaya çıkması yüksek olasılıktaki probleme yönelik çözüm öneriniz nelerdir? 


\section{EXTENDED ABSTRACT}

\section{The Views of Classroom Teachers for Use of Out-Of-School Learning Environments In Life Studies Course}

\section{Introduction}

There is a continuous development and change in the 21st century we are in. Although this change has a significant impact on schools, the role of the Life Studies course taught in primary schools cannot be denied. Life Studies course aims to gain knowledge, skills and values that enable the individual to adapt to community life (Gündoğan \& Gültekin, 2018). With the Life Studies course given in primary school, the student can prepare himself / herself for real life, program his / her life and bring solutions to the problems they face (Gündoğan \& Gültekin, 2018). In addition, Life Studies can be seen as important in terms of being the basis of Social Sciences and Science course. Life Studies course constitutes the basis of Science and Social Studies course (Baysal, Tezcan and Araç, 2018). As a result, the student may be inadequate in future classes due to a lack of learning in the previous classes. Especially in schools where constructivist understanding prevails, education is provided first hand. When examined in this respect, it is not enough to provide students with multiple different aspects such as life skills, interest in science and attitudes through books and teaching programs (Şen, 2019). Educators therefore went on different quests to teach the students of a complex structure the achievements of a course. This can be cited as an example of activities carried out in out-of-school learning environments. In particular, it encourages educators to out-of-school settings due to the nature of some of the gains that make it difficult to learn effectively in the classroom. Out-of-school learning is a kind of learning based on experience outside the school (Holm, 2017). In these environments, the student discovers, interprets, and ultimately constructs information. The majority of the course is theoretical; Out-of-school learning environments are the places where students can see, listen, and touch. Trainings conducted in out-of-school learning environments have positive effects on students' cognitive, affective and dynamic domains (Şen, 2019).

\section{Method}

As a method by researchers; descriptive research has been used since the class teachers who have taken their class to the out-of-school learning environment in the last five years have been investigated their thoughts on this practice. Descriptive research; It is the collection of data to identify features such as talents, beliefs, opinions and / or knowledge in the universe (Selçuk, 2019). In the descriptive study, the characteristics of the sample attitude, opinion, and behavior are described (Creswell, 2012; quoted. Selçuk, 2019).

\section{Findings, Result ve Discussion}

From this study; Third grade Life Studies course "Life in Nature" has a positive effect on "Learning by living "Life in Nature Unit Hayat is the s1 Complementary of My Education in the Class". It would be more effective to provide the Hayat Life in Nature i course in the 3rd year Life Studies course in the "Zoo and Natural Areas diş out-of-school learning environments, 3rd grade Life Studies course has more contribution to the discipline of olduğ Science veril especially in the delivery of ada Life in Nature Unit 1nda in out-of-school learning environments, Safety and Student Distractions fazla should be taken into consideration in order to give Hayat Life in Nature Unit i in 3rd grade Life Studies course in out-of-school learning 
environments, 3. Security and Distraction of Students olduğ is an important problem in the delivery of Hayat Life in Nature i course in 3rd grade Life Studies course in out-of-school learning environments, "Making a Good Planning yönelik for the problem that is most likely to arise in the delivery of the Hayat Life in Nature Unit 3. in the 3rd year Life Studies course in out-of-school learning environments has been given answers that problems can be overcome or solved.

Within the framework of the data from this study; It has been concluded that Out-of-School Learning Environments provide students first-hand knowledge by doing-living, and as a result, the learned knowledge is more permanent. However, it was concluded that it would not be sufficient to comprehend the subjects alone in the realization of the education outside the school environment and this should be supported with the theoretical knowledge given in the classroom. In addition, it is concluded that the lack of sufficient knowledge of the participants in the pre-trip, trip moment and post-trip applications stemmed from the fact that they did not receive any training on Out-of-School Learning Environments.

\section{Suggestion}

In the light of the results obtained in this study, the following suggestions can be made:

1. Based on the outcomes of the lessons, teachers will be able to, the education expenses of the teachers who passed the exam can be met by giving trainings on how to spend the time of the trip and the post-trip efficiently.

2. Pedagogical trainings can be given to guides in out-of-school learning environments.

3. Out-of-school environments can be redesigned in line with expert opinions in order to facilitate learning.

4. Classrooms where the school garden is suitable can process this unit in the garden.

5. The appropriate outcomes of all courses can be taught in out-of-school learning environments.

6. Other researchers who will study in this direction can take a sample group from different branches and study from different courses. 